\title{
Study on Road-Crossing Violations among Young Pedestrians Based on the Theory of Planned Behavior
}

\author{
Yun Xiao $\mathbb{D}^{1,2}$ Yang Liu $\mathbb{D}{ }^{1}$, and Zijun Liang $\mathbb{D}^{1,2}$ \\ ${ }^{1}$ School of Urban Construction and Transportation, Hefei University, Hefei 230606, Anhui, China \\ ${ }^{2}$ Anhui Province Transportation Big Data Analysis and Application Engineering Laboratory, Hefei 230606, Anhui, China
}

Correspondence should be addressed to Yun Xiao; xiaoyunhefei@163.com

Received 11 May 2021; Accepted 30 August 2021; Published 18 September 2021

Academic Editor: Xinqiang Chen

Copyright (c) 2021 Yun Xiao et al. This is an open access article distributed under the Creative Commons Attribution License, which permits unrestricted use, distribution, and reproduction in any medium, provided the original work is properly cited.

Young pedestrians have a high rate of traffic violations and are vulnerable. In this study, theory of planned behavior (TPB) questionnaires were collected from a sample of 395 young pedestrians. Reliability analysis demonstrated that the TPB questionnaire was effective and credible. An analysis model was established based on the TPB. The motivations for traffic violation behaviors among young pedestrians on intersections were studied from the perspective of social psychology. The results revealed that the most common violation behavior of young pedestrians was crossing on yellow light (29.7\%). Male young pedestrians reported the higher intention of violating regulations. Behavioral attitude (0.14), subjective norm (0.17), and perceived behavioral control (0.12) all affected young pedestrians' behavioral intentions. Relatives and friends played a positive role in mitigating young pedestrians' intentions to commit violations at intersections. Perceived behavior control had the weakest influence on young pedestrians' intentions to violate regulations. Behavioral intention (0.31) was the most direct and significant predictor of behavior. The results of the study are valuable for the identification of the causes of traffic violations among young pedestrians, and they can serve as a reference for the implementation of effective interventions.

\section{Introduction}

Intersections are key components of urban road traffic systems, and the traffic environment is highly complex. With the increases in the population and vehicles in Chinese cities, conflicts between pedestrians and drivers on intersections are becoming increasingly common, which severely affects safety. Pedestrian violations are a considerable hidden danger at urban intersections, with the potential to cause traffic accidents, traffic congestion, and other problems [1]. Pedestrians are vulnerable road users, and unsafe pedestrian behaviors likely cause personal injury and traffic accidents [2]. In 2018 alone, there were 3,045 traffic accidents involving pedestrians in China, resulting in 1,325 deaths and 1,968 injuries [3]. According to a road safety report published by the World Health Organization in 2018, more than 1000 people aged younger than 25 years die in road collision accidents every day worldwide. Road traffic injury is the main cause of death among young pedestrians, and vulnerable road user deaths comprise more than half of road traffic deaths [4]. Among developing countries, China had the highest annual number of traffic-related fatalities and injuries and many of these traffic incidents involved young pedestrians [5].

Some studies have revealed that intersection facilities are closely related to pedestrian violations. Ariane and Marie observed 400 adult pedestrians at two signalized and two unsignalized crossroads. They found that male pedestrians committed more violations than did female pedestrians; in particular, women tended to focus on other pedestrians, whereas men focused on vehicles [6]. Zhuang and $\mathrm{Wu}$ observed pedestrians at an unmarked roadway in China and found that pedestrians preferred crossing actively but with caution rather than waiting passively [7]. Jay et al. studied illegal pedestrian crossings at a signal light and revealed that Japanese pedestrians also hesitated longer when they were alone than when they were with others [8]. Brosseau et al. observed 13 intersections with similar geometry and traffic 
conditions but different maximum waiting times; the results indicated that an intersection clearing time influenced the violations and the proportion of dangerous crossings. Moreover, pedestrian speed depended on the type of crossing [9].

Individual pedestrian attributes are also directly related to violations. In a questionnaire survey of 205 students from two Israeli higher education institutions, Yagil revealed that women had a greater perception of their susceptibility to an accident resulting from an unsafe crossing than men. Moreover, both normative motivation and instrumental motivation predicted unsafe crossing behavior among men [10]. Jing reported that pedestrians can be classified into complex pedestrian groups based on differences in personal attributes. Pedestrians have different ways of crossing streets, different spaces for movement, and different delays before crossing the road [11]. Through statistical processing of traffic survey data, Yuan and Xiao demonstrated low awareness of traffic safety among pedestrians; gender, age, and driving license status had a strong influence on traffic safety awareness among pedestrians [12]. A study analyzed the basic psychology of pedestrians regarding road crossing and the road traffic environment and revealed that selfcentered thoughts, herd mentality, fluke mentality, and coveting personal convenience influence pedestrians when crossing a street in violation of regulations [13]. Lennon et al. reported that $20 \%$ of the recruited sample were likely to use a smart phone while crossing, which substantially increases the risk of accident. This behavior was especially prominent among those aged 18 to 30 years [14]. In another dataset of 67 recorded street crossings, approximately one-third were considered risky. Street-crossing decision-making is modulated by street-crossing habits, environmental configuration, social influence, understanding of the road situation, and driver behavior [15].

With the gradual increase in road-crossing violations among young pedestrians, some scholars have investigated the direct connections with individual characteristics. Zhou and Horrey showed that adolescent pedestrians had stronger road-crossing intentions when other pedestrians in the scenario are behaving in a consistent manner than in a situation where the behavior was not consistent with that of others [5]. Sullman et al. found that male adolescent reported more unsafe road-crossing behavior and playing on the roads, and their research also confirmed that unsafe road-crossing behavior increased with age [16]. Gou et al. claimed that road-crossing violations among young pedestrians are related to changes in attitudes and weak cognitive behavior control; the unique age attributes and immature and impulsive psychology of young pedestrians make them prone to illegal crossing behaviors [17]. A comparative analysis of young pedestrians and adult pedestrians can reveal the influence of attitudes and norms on crossing behavior. Compared with adults, young pedestrians are more likely to imitate the violation behaviors of pedestrians around them, and they are more sensitive to external perceptions and more likely to violate rules [18]. Gautam et al. revealed that lack of pavements and road crossings and obstructed paths increased adolescents' perception of injury risk; besides, speeding and a lack of respect for pedestrians by drivers were factors adolescents felt needed to be addressed [19]. It can be seen that performance of drivers on the road has a certain impact on the traffic safety of young pedestrians. The tendency of young pedestrians to commit violations and the high rates of violations and traffic accidents require special attention.

The theory of planned behavior (TPB) is an important analysis tool and it has been successfully applied to a wide range of health-related behaviors among adults and adolescents. Combining adolescent speeding specific model and TPB, Daniel et al. found that drivers who sped more in the past are most likely to speed more in the future and with less driving experience or with higher behavioral control speed less [20]. Cestac et al. used an extended version of the TPB to find determinants of the intention to speed were mostly attitude, normative variables, and past behavior and speeding intention increased with driving experience [21]. Horvath uses context-based TPB questionnaire data analysis to find that attitude and self-efficacy significantly predict intent, not just the variance explained by social demographic variables such as age, gender, self-esteem, sensory seeking, and past behavior and exposure [22]. The TPB has been successfully applied in the research of driving behavior, and it also has certain applicability in the field of young pedestrian safety. Gou et al. modified the TPB to study the illegal crossing behavior of young pedestrians, and they concluded that attitude and cognitive behavior control have significant positive impacts on the intention of young pedestrians to violate rules [17]. Zhou et al. established a regression model based on the TPB, which revealed two crossing intentions at intersections. Pedestrians with a high tendency of social consistency when crossing an intersection show a stronger intention to walk through the intersection for violations [23]. Evans and Norman used the TPB to predict young pedestrians' crossing intentions, and regression analyses revealed that the TPB explained $25 \%$ of the variance in road-crossing intentions. This exceeded the influence of age and gender, with perceived behavioral control emerging as the strongest predictor [24-26].

Above review indicates that the research on pedestrians has mainly focused on the road facilities environment, the basic characteristics of pedestrians, and pedestrian psychology. Analysis methods are mostly simple analysis of variance and regression analysis, and most studies have not thoroughly investigated the interactions between complex variables or have not performed targeted research based on specific characteristics [27-29]. Some studies have introduced the TPB into the field of pedestrian decision-making violations, but these studies have lacked in-depth analysis of young pedestrians' characteristics. Compared with other groups, young pedestrians tend to follow their peers (the public) at intersections, show greater risk-taking intentions without restraint, and have a higher frequency of distracted crossings.

Illegal behaviors among young pedestrians are more complex than those of adults because they include psychological factors in addition to behavior characteristics. The 
TPB and structural equation modeling (SEM) can be applied to complex multivariate models, and they are widely used in analyses of traffic behavior. In the present study, the TPB and SEM were adopted as analysis tools, with young pedestrians as the research object. A questionnaire survey was conducted at intersections to observe the mechanism of road-crossing violations among young pedestrians. The results can be used to improve traffic safety at urban intersections and to provide a Chinese research sample.

\section{Methods}

2.1. Research Hypothesis. As a classic theory of attitude-behavior relations, the TPB has been widely used in scientific research. The TPB was proposed by Ajzen and Fishbein, and it includes five elements, namely attitude toward behavior $(\mathrm{AB})$, subjective norms $(\mathrm{SN})$, perceived behavioral control (PBC), behavior intention (BI), and behavior (B) [30]. Attitude toward behavior refers to an individual's tendency to perform a certain behavior. Subjective norms refer to the perceived social pressure when deciding whether to perform a certain behavior. Perceived behavioral control refers an individual's perception of the ease of performing a certain behavior. This is an alternative measurement index that can replace actual control conditions and can directly predict the possibility of behavior. Behavioral intention refers to the subjective likelihood of an individual exhibiting the behavior, which reflects their willingness to implement it. Behavior refers to the individual's actual behavior [31].

Based on the TPB model and related results $[23,24]$, the following hypotheses regarding traffic violations at intersections are proposed (the related conceptual model is shown in Figure 1):

$\mathrm{H} 1$ : Behavioral intention regarding road-crossing violations among young pedestrians can be predicted by attitude toward behavior, subjective norms, and perceived behavior control.

$\mathrm{H} 2$ : Road-crossing violations among young pedestrians can be predicted by behavioral intention.

H3: Road-crossing violations among young pedestrians can be predicted by perceived behavioral control.

H4: Attitude toward behavior, subjective norms, and perceived behavioral control regarding road-crossing violation among young pedestrians positively influence behavioral intention.

H5: Perceived behavioral control and behavioral intention can predict road-crossing violation behavior among young pedestrians.

2.2. Investigation Process. The survey of road-crossing violations among young pedestrians comprised two parts, namely, an on-site observation, which was performed by 37 investigator, and an anonymous online questionnaire survey.
2.2.1. On-Site Investigation. A total of 16 intersections in 7 Chinese cities, namely, Hefei, Xi'an, Qingdao, An'qing, Chi'zhou, Lu'an, and Chu'zhou, were selected for field investigations. All selected intersections featured signal lights. The field survey was conducted that included peak and offpeak periods. The road environment, traffic conditions, and number of pedestrians at the 16 survey intersections differed, so the survey samples were representative.

Investigators recorded videos of 10 traffic light cycles at the intersections and abided by the relevant principles of objectivity, truthfulness, and safety. During the investigation period, 1067 pedestrians passed through the 16 intersections, including 483 male and 584 female pedestrians. Based on observations of pedestrian appearance, 420 pedestrians were aged younger than 30 years.

2.2.2. Questionnaire Survey. The questionnaire survey was distributed online, and a total of 472 responses were retrieved, of which 395 were valid, with an effective response rate of $83.7 \%$. All questionnaire survey results were completed anonymously, and no mandatory or incentive measures were applied. Questionnaires that were incomplete and those with obvious contradictions or repetitions were excluded, in order to avoid interference with research.

The questionnaire is an extremely important part of the report. The preliminary design is based on the questionnaires that have been practiced by the predecessors and have a certain applicability $[16,19,23,24]$. After a certain sample is investigated, the questions are appropriately deleted according to the results of the investigation. In order to further dig out the behavioral characteristics and related influencing factors of adolescents, taking into account the susceptibility of adolescents to the influence of others, the subjective norms design questions about family members, relatives, and friends and let the adolescents self-evaluate their behavioral intentions. The content included items related to basic personal characteristics and TPB variables. Personal characteristic attributes included gender, age, education, driver's license status, and car ownership. Moreover, items concerning traffic accident history and participation in traffic safety awareness training were included.

TPB variables were organized into five dimensions, namely, attitude toward behavior, subjective norms, perceived behavioral control, behavioral intention, and behavior. Each dimension included two to four items with strong explanatory power. All questions were answered on a 5-point Likert scale from 1 (strongly disagree) to 5 (strongly agree).

Items under attitude toward behavior assessed the respondents' beliefs and evaluations of road-crossing violations. Items under subjective norms assessed the motivations and beliefs contributing to the obedience of road-crossing rules. Items under perceived behavioral control assessed the respondents' beliefs about control and perceived strength. Items under behavioral intention assessed the respondents' intention to commit road-crossing violations. 


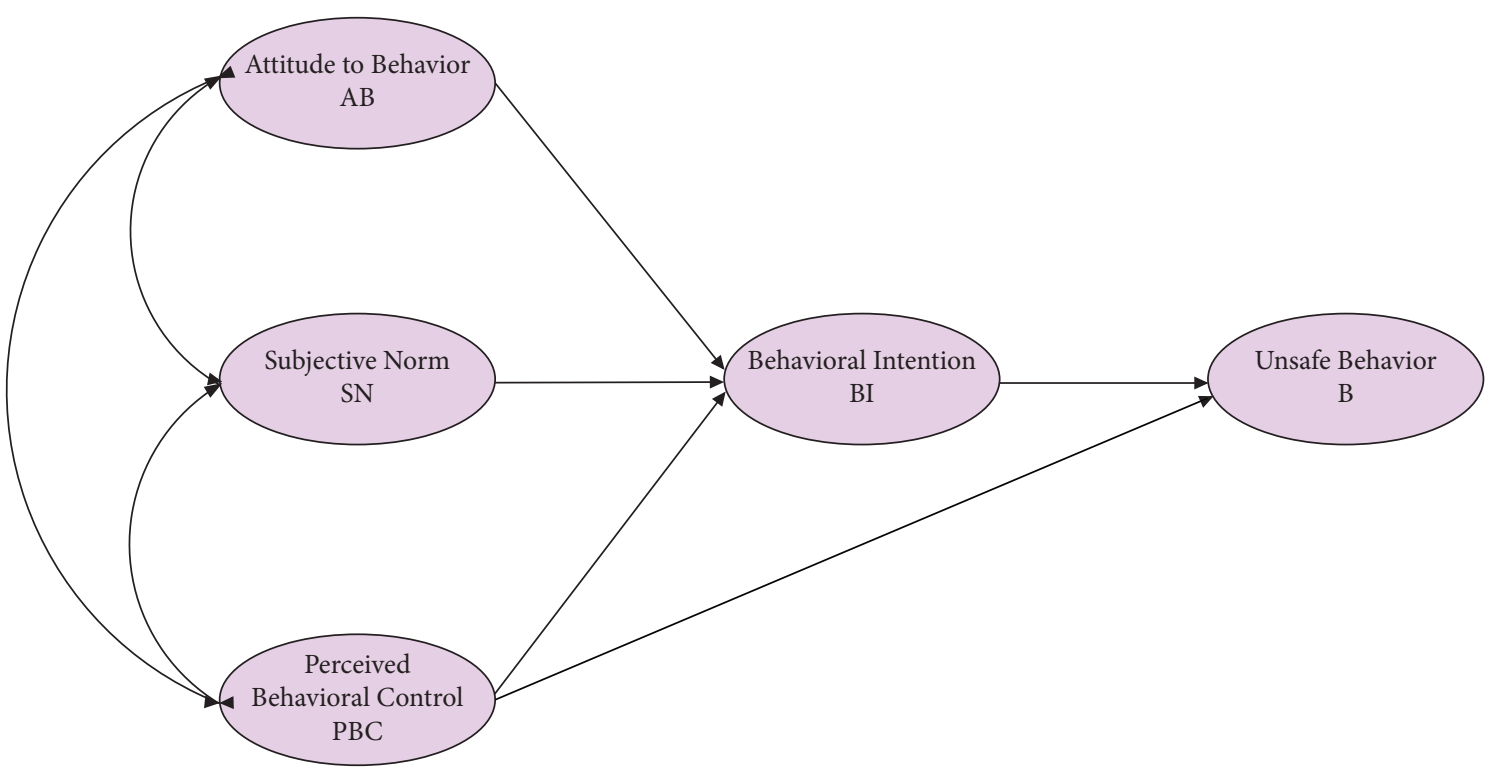

Figure 1: Conceptual model of road-crossing violations among young pedestrians based on the TPB.

Based on the proposed conceptual model and related studies on road-crossing violations, the final questionnaire featured five variables assessed using 15 items, as shown in Table 1.

\section{Results}

In this study, the SPSS 25.0 statistical analysis software package of IBM Corporation was used to obtain descriptive statistics and perform reliability and validity analyses of the survey data. AMOS 23.0 was adopted for modeling and path analysis.

3.1. On-Site Investigation and Analysis. In the field survey, the investigator roughly distinguishes the sample of teenagers through the appearance of pedestrians. The screening of later video analysis can basically identify young pedestrian samples.

The field investigation included 1067 pedestrians, and the overall violation rate was $28.7 \%$. The sample included 420 young pedestrians, with a violation rate of $34.8 \%$. Tables 2 and 3 list the statistics obtained from the on-site survey data and video records.

According to the analysis of the road-crossing violation recordings of young pedestrians, the following findings were obtained:

(1) The violation rate among young pedestrians was higher than that of the overall sample group by $6.1 \%$.

(2) Road-crossing violations committed by young pedestrians were jaywalking, not using zebra crossings, crossing on yellow light, looking down at a mobile phone while crossing the intersection, and failing to follow traffic signs. In addition, crossing on yellow light $(29.7 \%)$ and using a mobile phone while crossing the road $(23.2 \%)$ were the most common violations; crossing on yellow light was much more common than the remaining violations.
(3) The rate of road-crossing violations among young male pedestrians was $8.8 \%$ higher than that among young female pedestrians. Companion's violations were observed in 19 more male pedestrians than female pedestrians. Male pedestrians were strongly influenced by their companion's violations.

(4) Awareness of traffic safety among young pedestrians was weak; they even exhibited a tendency to ignore traffic rules and were easily influenced by other pedestrians. Distractions (e.g., using a mobile phone and listening to music) are common among young pedestrians when crossing intersections. Of the total violations, $22.7 \%$ involved companion, indicating the prominence of herd mentality. Young pedestrians were unwilling to wait for a green light (crossing on yellow light is a severe violation), which was due to the intention to save time and avoid trouble crossing the street.

3.2. Descriptive Statistics of the Questionnaire Survey. To describe the survey data and ensure the reliability, descriptive statistical analysis was performed on 395 valid questionnaires. Descriptive statistics revealed that the anonymous participants included 172 men (43.5\%) and 223 women $(56.5 \%)$; respondents aged 21 to 30 years accounted for $43.8 \%$, and those aged 20 years or younger accounted for $56.2 \%$. The majority of participants $(93.7 \%)$ had a college or undergraduate degree. Table 4 shows that $63.8 \%$ of the respondents had received education and training on traffic safety (mostly for the Chinese driving license examination), and $25.1 \%$ of the participants experienced traffic accidents.

3.3. Analysis of Variance. One-way analysis of variance was performed using SPSS 25.0 to determine the impact of personal attributes on the safety awareness of young pedestrians 
TABle 1: Questionnaire items.

\begin{tabular}{|c|c|c|}
\hline Constructs & Items & Measurement items (5-point scale) \\
\hline \multirow{3}{*}{ Attitude to behavior $(\mathrm{AB})$} & $\mathrm{AB} 1$ & When I violate traffic regulations, it will bring me feelings of anxiety or guilt. \\
\hline & $\mathrm{AB} 2$ & $\begin{array}{l}\text { When I encounter someone who violates traffic regulations on the road, I will be dissatisfied with } \\
\text { him. }\end{array}$ \\
\hline & AB3 & I feel that occasional traffic violations are inevitable. \\
\hline \multirow{4}{*}{ Subjective norm (SN) } & SN1 & When my family was there, they were very opposed to me breaking traffic rules. \\
\hline & SN2 & My family's opinion is important to prevent me from violating traffic regulations. \\
\hline & $\mathrm{SN} 3$ & $\begin{array}{l}\text { When a friend (colleague) was on the scene, the friend (colleague) was very opposed to my traffic } \\
\text { violation. }\end{array}$ \\
\hline & SN4 & I care about the opinions of my friends (colleagues). \\
\hline \multirow{3}{*}{$\begin{array}{l}\text { Perceived behavioral control } \\
(\mathrm{PBC})\end{array}$} & $\mathrm{PBC} 1$ & $\begin{array}{c}\text { When you break the rules at the crossroads, do you think you can easily handle the potential } \\
\text { danger of traffic? }\end{array}$ \\
\hline & $\mathrm{PBC} 2$ & When you violate traffic regulations at crossroads, do you worry about punishing the prosecutor? \\
\hline & PBC3 & $\begin{array}{c}\text { When you violate traffic regulations at crossroads, do you worry about causing dissatisfaction } \\
\text { with pedestrians? }\end{array}$ \\
\hline \multirow{3}{*}{ Behavioral intention(BI) } & BI1 & Next month, I might break the rules at a crossroads. \\
\hline & BI2 & Next month, I may break the traffic regulations for the convenience of walking. \\
\hline & BI3 & \\
\hline \multirow{2}{*}{ Unsafe behavior (B) } & B1 & Compared to pedestrians around you, you have more violations than them? \\
\hline & $\mathrm{B} 2$ & \\
\hline
\end{tabular}

TABle 2: Pedestrian data obtained from on-site survey at intersections.

\begin{tabular}{lcccccc}
\hline Items & $\begin{array}{c}\text { Total number of } \\
\text { pedestrians }\end{array}$ & $\begin{array}{c}\text { Total number of } \\
\text { male pedestrians }\end{array}$ & $\begin{array}{c}\text { Total number of } \\
\text { female } \\
\text { pedestrians }\end{array}$ & $\begin{array}{c}\text { Number of } \\
\text { pedestrian } \\
\text { violations }\end{array}$ & $\begin{array}{c}\text { Overall pedestrian } \\
\text { violation rate (\%) }\end{array}$ & $\begin{array}{c}\text { Male } \\
\text { violation rate } \\
(\%)\end{array}$ \\
\hline $\begin{array}{l}\text { Overall } \\
\text { situation }\end{array}$ & 1067 & 483 & 584 & 307 & 28.7 & 33.7 \\
$\begin{array}{l}\text { Youth } \\
\text { situation }\end{array}$ & 420 & 198 & 222 & 146 & 34.8 & 39.4 \\
\hline
\end{tabular}

TABLE 3: Illegal behaviors of young pedestrians observed at intersections.

\begin{tabular}{|c|c|c|c|}
\hline Items & Classification & Number of violations & Percentage of violations (\%) \\
\hline \multirow{2}{*}{ Running yellow light } & Male & 32 & \multirow{2}{*}{29.7} \\
\hline & Female & 19 & \\
\hline \multirow{2}{*}{ Cross the road to play on the phone or listen to music } & Male & 25 & \multirow{2}{*}{23.2} \\
\hline & Female & 15 & \\
\hline \multirow{2}{*}{ Do not take the zebra crossing or cross the road } & Male & 18 & \multirow{2}{*}{16.3} \\
\hline & Female & 10 & \\
\hline \multirow{2}{*}{ Running red light } & Male & 10 & \multirow{2}{*}{8.1} \\
\hline & Female & 4 & \\
\hline \multirow{2}{*}{ Companion's violations (may include the above violations) } & Male & 29 & \multirow[b]{2}{*}{22.7} \\
\hline & Female & 10 & \\
\hline
\end{tabular}

Note: some pedestrians may have violated multiple rules at the same time. The total number of violations by young pedestrians was 172 , and 146 young pedestrians committed at least one violation.

involved in road-crossing violations. The safety awareness level was obtained as the average of two questionnaire items related to safety behavior. The results are listed in Table 5 .

According to Table 5, the factor significantly affecting safety awareness was gender $(F=4.723, p<0.05)$. These results indicate that safety awareness was higher among female pedestrians than among young male pedestrians. Due to the large differences between the various types of samples with different education levels, the influencing factors are not considered for the time being.
The following general findings were obtained:

(1) Young female pedestrians have a higher level of safety awareness than their male counterparts do. Young females are generally more cautious when engaging in unsafe behaviors and have stronger selfcontrol.

(2) Judging from the scores of individual samples with lower education levels: Safety awareness is higher among young pedestrians with a higher educational 
Table 4: Demographic and descriptive statistical analysis $(N=395)$.

\begin{tabular}{|c|c|c|c|}
\hline Items & Classification & Number & Percentage (\%) \\
\hline \multirow{2}{*}{ Gender } & Male & 172 & 43.5 \\
\hline & Female & 223 & 56.5 \\
\hline \multirow{2}{*}{ Generation } & Under 20 & 222 & 56.2 \\
\hline & $21-30$ years old & 173 & 43.8 \\
\hline \multirow{4}{*}{ Education } & Junior high school or below & 4 & 1.0 \\
\hline & Technical secondary school or high school & 5 & 1.3 \\
\hline & College or undergraduate & 370 & 93.7 \\
\hline & Master's degree or above & 16 & 4.0 \\
\hline \multirow{2}{*}{ Domicile } & City & 129 & 32.7 \\
\hline & Rural area & 266 & 67.3 \\
\hline \multirow{2}{*}{ Driver's license } & Have & 122 & 30.9 \\
\hline & No & 273 & 69.1 \\
\hline \multirow{3}{*}{ Private car } & More than 1 & 58 & 14.7 \\
\hline & $1 \mathrm{car}$ & 176 & 44.6 \\
\hline & No & 161 & 40.7 \\
\hline \multirow{2}{*}{ Have you received traffic safety and related education and training } & Have & 252 & 63.8 \\
\hline & No & 143 & 36.2 \\
\hline \multirow{2}{*}{ Have you ever experienced a traffic accident } & Have & 99 & 25.1 \\
\hline & No & 296 & 74.9 \\
\hline
\end{tabular}

TABLE 5: Analysis of variance for safety awareness among young pedestrians $(N=395)$.

\begin{tabular}{|c|c|c|c|c|}
\hline \multirow[b]{2}{*}{ Items } & \multirow[b]{2}{*}{ Classification } & \multicolumn{3}{|c|}{ Level of safety awareness } \\
\hline & & $\begin{array}{l}\text { Average } \\
\text { value }\end{array}$ & $F$ value & $P$ \\
\hline Gender & $\begin{array}{c}\text { Male } \\
\text { Female }\end{array}$ & $\begin{array}{l}4.1279 \\
4.3004\end{array}$ & 4.723 & $0.030^{*}$ \\
\hline Generation & $\begin{array}{c}\text { Under } 20 \\
21-30 \text { years old }\end{array}$ & $\begin{array}{l}4.2523 \\
4.1908\end{array}$ & 0.595 & 0.441 \\
\hline Education & $\begin{array}{c}\text { Junior high school or below } \\
\text { Technical secondary school or high } \\
\text { school } \\
\text { College or undergraduate } \\
\text { Master's degree or above }\end{array}$ & $\begin{array}{l}3.2500 \\
3.7000 \\
4.2514 \\
4.0313 \\
\end{array}$ & 3.315 & $0.020^{*}$ \\
\hline Domicile & $\begin{array}{c}\text { City } \\
\text { Rural area }\end{array}$ & $\begin{array}{l}4.2054 \\
4.2350 \\
\end{array}$ & 0.122 & 0.727 \\
\hline Driver's license & $\begin{array}{l}\text { Yes } \\
\text { No }\end{array}$ & $\begin{array}{l}4.2254 \\
4.2253\end{array}$ & 0.000 & 0.999 \\
\hline Private car & $\begin{array}{c}\text { More than } 1 \\
1 \text { car } \\
\text { No } \\
\end{array}$ & $\begin{array}{l}4.1293 \\
4.2386 \\
4.2453 \\
\end{array}$ & 0.509 & 0.602 \\
\hline $\begin{array}{l}\text { Have you received traffic safety and related education and } \\
\text { training }\end{array}$ & $\begin{array}{l}\text { Yes } \\
\text { No }\end{array}$ & $\begin{array}{l}4.2361 \\
4.2063\end{array}$ & 0.131 & 0.718 \\
\hline Have you ever experienced a traffic accident & $\begin{array}{l}\text { Yes } \\
\text { No }\end{array}$ & $\begin{array}{l}4.1465 \\
4.2517\end{array}$ & 1.331 & 0.249 \\
\hline
\end{tabular}

${ }^{*} p<0.05$.

level than among those with a lower educational level. Low safety awareness is associated with insufficient knowledge among young pedestrians with a lower educational level.

3.4. Reliability and Validity of the Questionnaire. In this study, SPSS 25.0 was used to assess the reliability and validity of the questionnaire and to perform exploratory factor analysis (EFA) of the data.

Reliability analysis of the questionnaire yielded an overall Cronbach's alpha of 0.822 . Attitude toward behavior, subjective norms, perceived behavioral control, behavioral intention, and behavior had internal consistency values of $0.758,0.855,0.877,0.835$, and 0.897 , respectively. The within-group Cronbach's alpha coefficients were higher than 
0.7 for all dimensions, indicating that the survey data were acceptably reliable and that all dimensions had high internal consistency. The results are shown in Table 6.

Before performing factor analysis, the Kaiser-Meyer-Olkin (KMO) test and Bartlett's test were performed on the survey data. The results are shown in Table 7. The KMO result was 0.759 , which was higher than 0.7 , and Bartlett's test yielded a significant result $(p<0.05)$. The results were all within their effective index ranges, indicating that the original variables are suitable for factor analysis [32].

Principal component analysis was used to extract factors and then select those with characteristic root values greater than 1 . The initial solution of the output factor is shown in Table 8. The common variance of AB4 was only 0.277 , indicating substantial loss of variable information (nearly $70 \%$ ); this factor extraction was not ideal. The correlations of $\mathrm{AB} 4$ with the other three variables in the dimension of attitude toward behavior (i.e., $\mathrm{AB} 1, \mathrm{AB} 2$, and $\mathrm{AB} 3$ ) were low, indicating that $\mathrm{AB} 4$ was inconsistent overall the questionnaire. Therefore, $\mathrm{AB} 4$ was removed and the factor analysis was repeated.

The quality of second factor extraction was higher, and most of the variable information was retained. Principal component analysis yielded five factors explaining $75.816 \%$ of the total variance. Table 9 lists the extraction results (variables with coefficients of $<0.4$ were excluded).

3.5. Model Construction. Based on the TPB, the attitude toward behavior, subjective norms, and perceived behavioral control predicted behavioral intention among young pedestrians. SEM is suitable for the exploration and analysis of complex multivariate data [33]; it can be used to analyze the role of each indicator and the relationships between indicators.

The observed variables and latent variables for the model were obtained through EFA of the questionnaire data, and AMOS 23.0 was used to establish a structural path diagram for road-crossing violation behaviors among young pedestrians (Figure 2). Rectangles, ellipses, circles, one-way arrows, and two-way arc arrows represent observed variables, latent variables, error variables, one-way effects, and correlations, respectively. All path coefficients in the diagram are standardized path coefficients (standardization factor loading).

The fit indicators for the structural model, namely, chi-square/degree of freedom (CMIN/DF), root mean square error of approximation (RMSEA), root mean square error test of close fit (PCLOSE), goodness-of-fit index (GFI), adjusted goodness-of-fit index (AGFI), comparative fit index (CFI), and normed fit index (NFI) were adopted based on the evaluation criteria proposed by $\mathrm{Wu}$ [34]. These indicators were all within their acceptable standard ranges (Table 10), indicating the authenticity of path analysis. The high fit revealed that the TPB explained the road-crossing violation behaviors of young pedestrians.
TABLE 6: Cronbach's alpha coefficients of the research variables.

\begin{tabular}{lcccccc}
\hline Dimension & $\mathrm{AB}$ & $\mathrm{SN}$ & $\mathrm{PBC}$ & $\mathrm{BI}$ & $\mathrm{B}$ & Overall \\
\hline$\alpha$ & 0.758 & 0.855 & 0.877 & 0.835 & 0.897 & 0.822 \\
\hline
\end{tabular}

TABLE 7: KMO and Bartlett's tests.

\begin{tabular}{lcc}
\hline \multicolumn{3}{c}{ KMO and Bartlett test } \\
\hline KMO sampling appropriateness quantity & 0.759 \\
\hline \multirow{3}{*}{ Bartlett test } & Approximate chi-square & 2865.817 \\
& Degree of freedom & 105 \\
& Significance & .000 \\
\hline
\end{tabular}

TABLE 8: First solution to factor analysis.

\begin{tabular}{lcc}
\hline & First common factor variance \\
Items & Initial & Extract \\
\hline AB1 & 1.000 & 0.599 \\
AB2 & 1.000 & 0.604 \\
AB3 & 1.000 & 0.744 \\
AB4 & 1.000 & 0.277 \\
SN1 & 1.000 & 0.644 \\
SN2 & 1.000 & 0.769 \\
SN3 & 1.000 & 0.603 \\
SN4 & 1.000 & 0.793 \\
PBC1 & 1.000 & 0.835 \\
PBC2 & 1.000 & 0.760 \\
PBC3 & 1.000 & 0.725 \\
BI1 & 1.000 & 0.855 \\
BI2 & 1.000 & 0.838 \\
BI3 & 1.000 & 0.870 \\
B1 & 1.000 & 0.811 \\
B2 & 1.000 & 0.800 \\
\hline
\end{tabular}

Extraction method: principal component analysis method.

TABLE 9: Factor loading matrix after rotation.

\begin{tabular}{|c|c|c|c|c|c|}
\hline & & ted co & nent m & & \\
\hline Items & & & ngredie & & \\
\hline HenIs & 1 & 2 & 3 & 4 & 5 \\
\hline SN4 & 0.878 & - & - & - & - \\
\hline SN2 & 0.858 & - & - & - & - \\
\hline SN1 & 0.791 & - & - & - & - \\
\hline SN3 & 0.753 & - & - & - & - \\
\hline PBC1 & - & 0.918 & - & - & - \\
\hline PBC2 & - & 0.845 & - & - & - \\
\hline PBC3 & - & 0.815 & - & - & - \\
\hline BI2 & - & - & 0.869 & - & - \\
\hline $\mathrm{BI} 3$ & - & - & 0.846 & - & - \\
\hline BI1 & - & - & 0.832 & - & - \\
\hline AB3 & - & - & - & 0.856 & - \\
\hline $\mathrm{AB} 2$ & - & - & - & 0.802 & - \\
\hline $\mathrm{AB} 1$ & - & - & - & 0.743 & - \\
\hline B2 & - & - & - & - & 0.936 \\
\hline B1 & - & - & - & - & 0.933 \\
\hline
\end{tabular}

3.6. Analysis of SEM Results. The structural equation model of road-crossing violation behaviors among young pedestrians yielded the following formulas: 


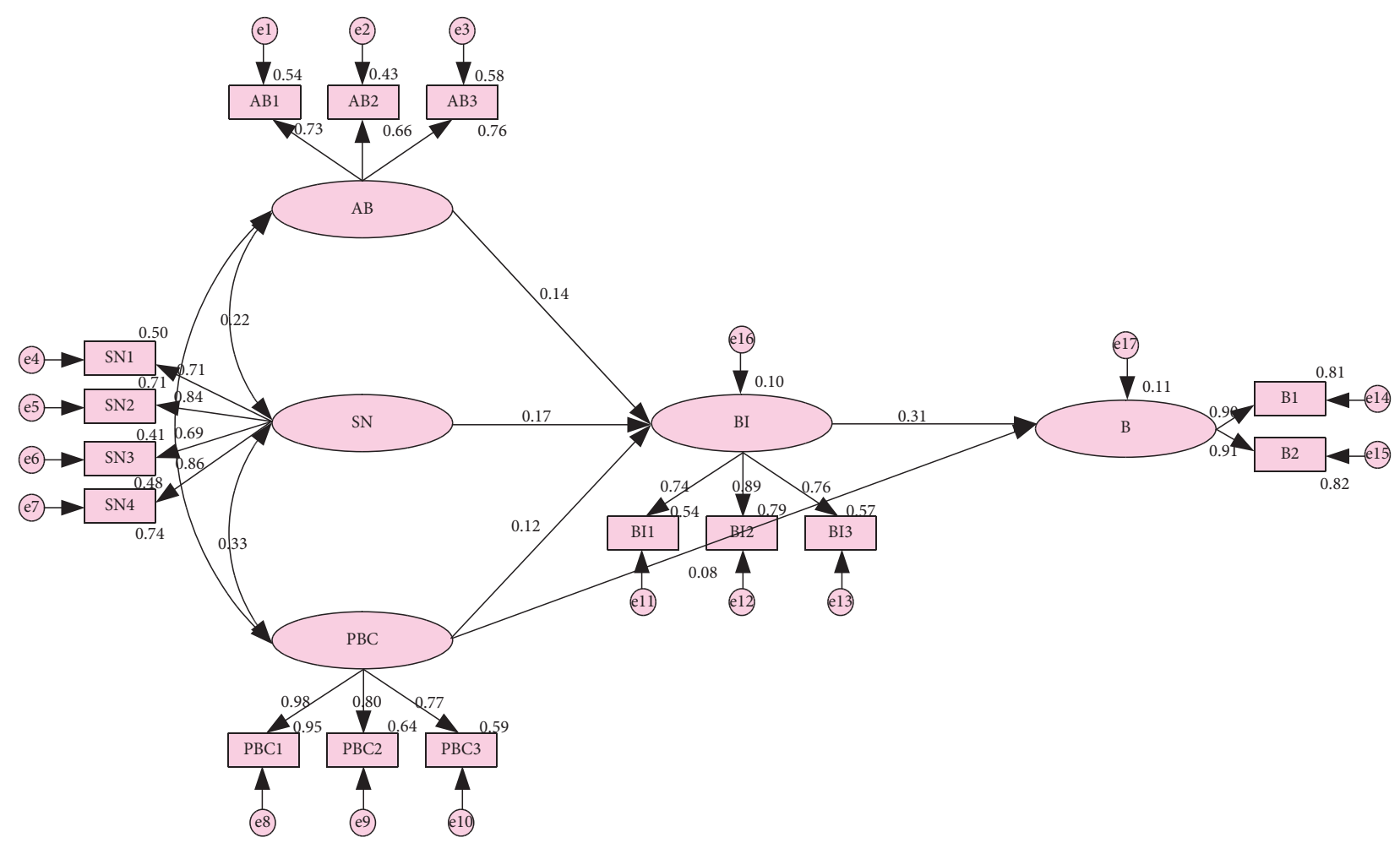

FIGURE 2: Structural equation model of road-crossing violation behaviors among young pedestrians.

TABLE 10: Fit indices for the structural equation model.

\begin{tabular}{|c|c|c|c|c|c|c|c|}
\hline Fitting index & CMIN/DF & RMSEA & PCLOSE & GFI & AGFI & CFI & NFI \\
\hline Adaptation standard & $1-3$ & $<0.05$ & $>0.05$ & $>0.9$ & $>0.9$ & $>0.9$ & $>0.9$ \\
\hline Model results & 1.661 & 0.041 & 0.890 & 0.957 & 0.937 & 0.981 & 0.953 \\
\hline Fitting result & Good & Good & Good & Good & Good & Good & Good \\
\hline
\end{tabular}

$$
\begin{aligned}
\mathrm{BI} & =0.14 \mathrm{AB}+0.17 \mathrm{SN}+0.12 \mathrm{PBC}, \\
\mathrm{B} & =0.31 \mathrm{BI}+0.08 \mathrm{PBC},
\end{aligned}
$$

where $\mathrm{BI}, \mathrm{AB}, \mathrm{SN}, \mathrm{PBC}$, and $\mathrm{B}$ represent behavioral intention, attitude toward behavior, subjective norms, perceived behavioral control, and behavior, respectively. The SEM diagram and these expressions reveal the following findings:

(1) Attitude toward behavior, subjective norms, and perceived behavioral control significantly positively influence road-crossing violations among young pedestrians.

(2) Behavioral intentions have a significant positive impact on road-crossing violation among young pedestrians.

(3) Perceived behavioral control significantly positively impacts road-crossing violations among young pedestrians.

\section{Discussion}

In this study, a comprehensive analysis of road-crossing violations among young pedestrians was conducted through field surveys and based on the TPB. This section provides the results of related studies on road-crossing violations among young pedestrians, and their results are compared with those of the present study.

A previous study indicated that women are more sensitive to pedestrian violations [10], which is consistent with the low rate of peer violations (5.8\%) among young women in the present field survey. Young women exhibited less herd mentality than their male counterparts, and they committed fewer violations. Sensitivity to violations results in fewer violations and a greater willingness to maintain intersection safety.

Liu et al. identified herd mentality and fluke mentality among pedestrians at intersections [13], which is consistent with the present field survey findings of the herd mentality (peer violation rate of $22.7 \%$ ) and fluke violations. The high rate of yellow light violations (29.7\%) indicated that young pedestrians perceive yellow light as a safe traffic environment. On the other hand, because there are no clear penalties for running a yellow light in China, there is no corresponding restriction, making young pedestrians more daring and risky in violation.

This reflects fluke mentality regarding road crossing and a disregard for traffic laws. In addition, the high rate of road crossing while using a mobile phone by young pedestrians (23.2\%) was consistent with the results of Lennon [14]. The 
level of distraction is increased by mobile phone use, and distraction can cause road accidents. Reducing the distraction of young pedestrians is an effective approach to improving intersection safety.

Previous studies have found that age and driver's license status impact awareness of traffic safety and violations among pedestrians $[12,13]$; however, the results of the present study differed slightly from this conclusion. This is mainly because the research object of this paper is adolescents, whose overall age span is small and concentrated in the fixed age group. In terms of driver's license, Chinese teenagers who hold a driver's license actually drive fewer cars and do not have a lot of opportunities to practice driving. There is no significant difference in safety awareness between teenagers whether or not they have driver's license. However, gender $(F=4.723, p<0.05)$ had significant effects, and this is consistent with previous research results $[1,6]$. Young women exhibited a higher level of safety awareness $($ mean $=4.3004)$ than their male counterparts (mean$=4.1279$ ), and they committed fewer violations. Therefore, improving relevant knowledge and vigilance among young male pedestrians would reduce the occurrence of unsafe behaviors.

The present results indicated that the TPB model can predict and explain pedestrian road-crossing violations, which is consistent with the findings of previous studies $[20,23,24]$. The current results confirm those of previous studies by revealing that attitude toward behavior, subjective norms, and perceived behavioral control can predict young pedestrians' behavioral intention for road-crossing violation behavior. In addition, road-crossing violations can be predicted by behavioral intention and perceived behavioral control. Therefore, H1-3 are supported.

The influence of attitude toward behavior on the behavioral intention among young pedestrians was 0.14 ; this is one of the effective predictors of behavioral intention. This result is in agreement with those of related studies $[21,22,24,35]$, in which attitude toward behavior was reported to predict behavioral intention. The present study revealed that young pedestrians do not pay sufficient attention to some violations. They believe that occasional violations at intersections are inevitable $(\mathrm{AB} 3=0.76)$; this attitude will lead to more frequent traffic violations by teenagers. Another study [17] shows that young pedestrians are more likely to change their attitude than adults, so it is very important to strengthen teenagers' education and cultivate teenagers' traffic safety awareness.

The impact of subjective norms on road-crossing violation behavioral intention among young pedestrians was 0.19 ; this was another important predictor of behavioral intention, with the strongest explanatory power. This result is in agreement with those of a previous study $[21,36]$ but contrasted with those of Evans and Norman [24, 36], who claimed that subjective norms have no significant correlation with behavioral intention among young pedestrians. However, for most of the young pedestrians surveyed in the present study, their friends and family members opposed and rejected unsafe road-crossing behaviors $(\mathrm{SN} 2=0.84$, $\mathrm{SN} 4=0.86$ ). Because subjective norms reflect social pressure
[31], moral constraints, and personal psychological struggles, young pedestrian groups often make positive and good behaviors under social pressure under restraint. The opinions of friends and family members have a strong impact on young pedestrians; safety improvement measures should include the active intervention of family and friends; this can raise awareness of road-crossing violations among young pedestrians in terms of ethics.

The influence of perceived behavior control on the intention to commit road-crossing violations was 0.12 , and the influence on the behavior itself was 0.08. Compared with attitude and subjective norms, the explanatory power of perceived behavior control was low, and this was the weakest predictor of intention to commit road-crossing violations. This is inconsistent with the results of previous studies $[23,24,37]$, which have indicated that perceived behavior control is an important predictor of behavioral intention among pedestrians. However, this does not seem to apply to young pedestrians. Therefore, enhancing the influence of perceived behavioral control is an effective way to limit irregular behaviors among young pedestrians. Intention to commit road-crossing violations among young pedestrians is affected by perceived behavioral control $(0.12)$. The influence of perceived behavior control on behavior was 0.08 . Perceived behavioral control can bypass behavioral intention and directly affect behavior among young pedestrians, which has weak external perception ability. Improving the ability to control perception and behavior can reduce the frequency of unsafe behaviors among young pedestrians and effectively improve the urban traffic environment.

The influence of behavioral intention on road-crossing violations among young pedestrians was 0.31 . This was the most direct and important predictor of behavior, indicating that good behavioral intentions can effectively reduce roadcrossing violations among young pedestrians. Previous studies produced similar results $[18,23,24,38]$. BI2 was the most important observational variable for behavioral intention (0.89), indicating that many young pedestrians believe that they may violate the rules for the convenience of walking in the future and they subjectively judge that they will violate traffic rules in the future. The behavioral intentions of young pedestrians are relatively intuitive. Through their self-reports, they can truly know their tendency toward behavioral intentions, and it can be known that the quality of their behavioral intentions directly determines the positive or negative behaviors of young pedestrians. Therefore, improving behavioral intentions is crucial for improving safety awareness among young pedestrians.

This research targeted young pedestrians in some Chinese cities, and conclusions can be generalized to young pedestrians in most areas of China. At present, safety education for children pedestrians and young pedestrians often focuses on traffic rules [23], and they lack subjective awareness and cognition of road-crossing violations. Young pedestrians should be encouraged to correctly understand the severe consequences of violating traffic rules and improve their attitude and cognition. Promoting the positive role of friends and relatives in regulating young pedestrians 
and strengthening young pedestrians' awareness of the traffic environment can reduce road-crossing violations among young pedestrians.

\section{Conclusions}

Road-crossing violations are a social issue that must be considered, different mechanisms may explain these violations in difference social groups, and the rate of roadcrossing violations is gradually increasing among young pedestrians. Therefore, the present study conducted on-site investigations and distributed questionnaires to investigate road-crossing violations among young pedestrians. The mechanism and characteristics violations were explored using SEM. The conclusions are summarized as follows:

(1) The rate of road-crossing violations is higher among young pedestrians $(34.8 \%)$ than the overall group (28.7\%). Crossing on yellow light was the most common violation among young pedestrians (29.7\%) along with using a mobile phone while crossing $(23.2 \%)$. The rate of violations was higher among male young pedestrians (39.4\%) than among female young pedestrians (30.6\%). Male young pedestrians exhibited the lower safety awareness and the higher intention to violate regulations. The behavioral characteristics of this group of pedestrians require urgent attention.

(2) The structural equation model based on the TPB revealed that subjective norms were the most important factor for predicting intention to violate the rules among young pedestrians. Friends and relatives had the greatest positive influence on subjective norms. Perceived behavioral control had a lower explanatory power on behavioral intentions, indicating that the explanatory power of such indicators could be improved in order to restrain violation behaviors. Behavioral intention was the most important predictor of violation behaviors in the model. These results may be valuable for identifying the incentives to reduce road-crossing violations and to conduct effective interventions.

\section{Limitations}

This study had certain limitations for obtaining large samples in surveys of young pedestrians, so the sample size of the questionnaire was relatively small, thus limiting the persuasiveness of the results. The larger the sample size is, the more representative it is. The present results may be limited to young pedestrians in some regions of China. A more comprehensive survey of young pedestrians in other countries and regions is therefore needed in the future. Study was based on the self-reported data; despite anonymity, the questionnaire respondents maybe cannot answer objectively. The questionnaire design was not sufficiently comprehensive; questions in some dimensions did not have strong explanatory power. Therefore, future studies should improve the existing survey methods. The present model only included the dimensions of attitude toward behavior, subjective norms, and perceived behavioral control, and discussion and exploration of other influencing factors were lacking. Future studies should be recommended to include a wide survey base, enriched survey samples, and more comprehensive survey methods to investigate additional factors and latent variables, such as punishment avoidance, external perception, and the traffic environment.

\section{Data Availability}

All the relevant data are within the manuscript.

\section{Conflicts of Interest}

The authors declare that they have no conflicts of interest.

\section{References}

[1] F. Wang, "Research on intention of pedestrians violation crossing the street based on the basis of planned behavior theory," Master Thesis, Southwest Jiaotong University, Sichuan, China, 2018.

[2] M. Mahdi, K. Abdoljavad, D. Leila, and P. D. Saeid, "Red light violation and pedestrians' modal salient beliefs about unsafe road crossing behavior: a qualitative study," Journal of Injury and Violence Research, vol. 11, no. 2, pp. 189-202, 2019.

[3] D. Ma, Y. L. Pei, and K. Tian, "Literature review of pedestrian traffic safety research based on bibliometric analysis," China Safety Science Journal, vol. 30, no. 8, pp. 101-108, 2020.

[4] World Health Organization, Global Status Report on Road Safety 2018, World Health Organization, Geneva, Switzerland, 2018, https://apps.who.int/iris/handle/10665/276462.

[5] R. Zhou and W. J. Horrey, "Predicting adolescent pedestrians' behavioral intentions to follow the masses in risky crossing situations," Transportation Research Part F: Traffic Psychology and Behaviour, vol. 13, no. 3, pp. 153-163, 2010.

[6] A. Tom and M.-A. Granié, "Gender differences in pedestrian rule compliance and visual search at signalized and unsignalized crossroads," Accident Analysis \& Prevention, vol. 43, no. 5, pp. 1794-1801, 2011.

[7] X. Zhuang and C. Wu, "Pedestrians' crossing behaviors and safety at unmarked roadway in China," Accident Analysis \& Prevention, vol. 43, no. 6, pp. 1927-1936, 2011.

[8] M. Jay, A. Régnier, A. Dasnon, K. Brunet, and M. Pelé, “The light is red: uncertainty behaviours displayed by pedestrians during illegal road crossing," Accident Analysis \& Prevention, vol. 135, Article ID 105369, 2020.

[9] M. Brosseau, S. Zangenehpour, N. Saunier, and L. MirandaMoreno, "The impact of waiting time and other factors on dangerous pedestrian crossings and violations at signalized intersections: a case study in Montreal," Transportation Research Part F: Traffic Psychology and Behaviour, vol. 21, pp. 159-172, 2013.

[10] D. Yagil, "Beliefs, motives and situational factors related to pedestrians' self-reported behavior at signal-controlled crossings," Transportation Research Part F: Traffic Psychology and Behaviour, vol. 3, no. 1, pp. 1-13, 2000.

[11] C. Jing, Study on Pedestrians Crossing Characteristics. Doctor, Jilin University, Jilin China, 2007.

[12] H. W. Yuan and G. P. Xiao, "Study on the unsafe behaviors of pedestrians based on traffic psychology," China Safety Science Journal, vol. 18, no. 1, pp. 20-26+179, 2008. 
[13] G. X. Liu, K. P. Li, and Y. Ni, "An overview on pedestrian psychology and behavior when crossing intersections," Journal Technology \& Economy in Areas of Communications, no. 5, pp. 58-61, 2008.

[14] A. Lennon, O. Oviedo-Trespalacios, and S. Matthews, "Pedestrian self-reported use of smart phones: positive attitudes and high exposure influence intentions to cross the road while distracted," Accident Analysis \& Prevention, vol. 98, pp. 338-347, 2017.

[15] S. Cougnet, B. Cahour, and S. Kraiem, "Risk-taking, emotions and socio-cognitive dynamics of pedestrian streetcrossing decision-making in the city," Transportation Research Part F: Traffic Psychology and Behaviour, vol. 65, pp. 141-157, 2019.

[16] M. J. M. Sullman, M. E. Gras, S. Font-Mayolas, L. Masferrer, M. Cunill, and M. Planes, "The pedestrian behaviour of Spanish adolescents," Journal of Adolescence, vol. 34, no. 3, pp. 531-539, 2011.

[17] J. Q. Gou, Q. G. Zou, and L. Wang, “An analysis of teenagers' traffic violation behavior based on the improved theory of planned behavior," Journal of Beijing Jiaotong University (Social Science Edition), vol. 11, no. 3, pp. 85-90+110, 2012.

[18] Q. G. Zou, "The analysis of traffic behavior based on the improved TPB (theory of planned behavior)," Master Thesis, Beijing Jiaotong University, Beijing China, 2011.

[19] P. Gautam, J. A. Mytton, S. K. Joshi, and P. Pilkington, "Adolescent's perception of road risk on their routes to school in Makwanpur, Nepal; a qualitative study," Journal of Transport \& Health, vol. 20, Article ID 101009, 2021.

[20] D. Vankov, R. Schroeter, and D. Twisk, "Understanding the predictors of young drivers' speeding intention and behaviour in a three-month longitudinal study," Accident Analysis \& Prevention, vol. 151, Article ID 105859, 2021.

[21] J. Cestac, F. Paran, and P. Delhomme, "Young drivers' sensation seeking, subjective norms, and perceived behavioral control and their roles in predicting speeding intention: how risk-taking motivations evolve with gender and driving experience," Safety Science, vol. 49, no. 3, pp. 424-432, 2011.

[22] C. Horvath, I. Lewis, and B. Watson, "Peer passenger identity and passenger pressure on young drivers' speeding intentions," Transportation Research Part F: Traffic Psychology and Behaviour, vol. 15, no. 1, pp. 52-64, 2012.

[23] R. Zhou, W. J. Horrey, and R. Yu, "The effect of conformity tendency on pedestrians' road-crossing intentions in China: an application of the theory of planned behavior," Accident Analysis \& Prevention, vol. 41, no. 3, pp. 491-497, 2009.

[24] D. Evans and N. Paul, "Predicting adolescent pedestrians' road-crossing intentions: an application and extension of the theory of planned behaviour," Health Education Research, vol. 18, no. 3, pp. 267-277, 2003.

[25] X. Chen, L. Qi, Y. Yang et al., "Video-based detection infrastructure enhancement for automated ship recognition and behavior analysis," Journal of Advanced Transportation, vol. 2020, Article ID 7194342, 12 pages, 2020.

[26] R. W. Liu, W. Yuan, X. Chen, and Y. Lu, "An enhanced CNNenabled learning method for promoting ship detection in maritime surveillance system," Ocean Engineering, vol. 235, Article ID 109435, 2021.

[27] X. Chen, H. Chen, Y. Yang et al., "Traffic flow prediction by an ensemble framework with data denoising and deep learning model," Physica A: Statistical Mechanics and Its Applications, vol. 565, no. 9, Article ID 125574, 2021.
[28] B. Wu, Y. Tang, X. Yan, and C. Guedes Soares, "Bayesian network modelling for safety management of electric vehicles transported in RoPax ships," Reliability Engineering \& System Safety, vol. 209, no. 2, Article ID 107466, 2021.

[29] X. Chen, Z. Li, Y. Yang, L. Qi, and R. Ke, "High-resolution vehicle trajectory extraction and denoising from aerial videos," IEEE Transactions on Intelligent Transportation Systems, vol. 22, no. 5, pp. 3190-3202, 2021.

[30] I. Ajzen, "The theory of planned behavior," Organizational Behavior and Human Decision Processes, vol. 50, no. 2, pp. 179-211, 1991.

[31] W. T. Duan and G. R. Jiang, "A review of the theory of planned behavior," Journal of Advances in Psychological Science, vol. 18, no. 2, pp. 315-320, 2008.

[32] W. Xue, SPSS Statistical Analysis Method and Application, Publishing House of Electronics Industry, Beijing, China, 4th edition, 2017.

[33] T. S. Rong, AMOS and Research Methods, Chongqing University Press, Chongqing, China, 2nd edition, 2017.

[34] M. L. Wu, Operation and Application of Structural Equation Model AMOS, Chongqing University Press, Chongqing, China, 1st edition, 2010.

[35] B. K. Barton, S. M. Kologi, and A. Siron, "Distracted pedestrians in crosswalks: an application of the theory of planned behavior," Transportation Research Part F: Traffic Psychology and Behaviour, vol. 37, pp. 129-137, 2016.

[36] D. Evans and P. Norman, "Understanding pedestrians' road crossing decisions: an application of the theory of planned behaviour," Health Education Research, vol. 13, no. 4, pp. 481-489, 1998.

[37] K. Verswijvel, W. Heirman, M. Walrave, and K. Hardies, "Understanding adolescents' unfriending on Facebook by applying an extended theory of planned behaviour," Behaviour \& Information Technology, vol. 38, no. 8, pp. 807-819, 2018.

[38] H. Zhou, S. B. Romero, and X. Qin, "An extension of the theory of planned behavior to predict pedestrians' violating crossing behavior using structural equation modeling," Accident Analysis \& Prevention, vol. 95, pp. 417-424, 2016. 